\title{
Cost of Illness of Breast Cancer Patients on Chemotherapy in Addis Ababa Public Hospitals, the Case of Tikur Anbessa Specialized Teaching Hospital-Cross-Sectional Types of Study
}

Gezahegn Mamo ${ }^{1 *}$, Alemayehu Worku², Seblewengel Lemma ${ }^{3}$ and Tangut Demas ${ }^{4}$

${ }^{1}$ Department of Health Economics, St. Paul's Hospital Millennium Medical College, Addis Ababa University, Ethiopia

${ }^{2}$ Department of Biostatistics, St. Paul's Hospital Millennium Medical College, Addis Ababa University, Ethiopia

${ }^{3}$ International institute for Primary Health, St. Paul's Hospital Millennium Medical College, Addis Ababa University, Ethiopia

${ }^{4}$ Department of Specialty Nursing, St. Paul's Hospital Millennium Medical College, Addis Ababa University, Ethiopia

\begin{abstract}
Background: Breast cancer is the most commonly diagnosed cancer and the second most leading cause of death next to cervical cancer in Ethiopia. An economic burden of breast cancer is a considerable issue in most middle and low income countries, especially in Ethiopia, where there is high out-of-pocket expenditure for health.

Objectives: To estimate Economic burden of breast cancer patients on chemotherapy attending at Tikur Anbessa Specialized Teaching Hospital (TASH) and to determine Predictors for variation in patient related cost of breast cancer patients on chemotherapy.

Methods: The Cost of illness study on 349 breast cancer cases was carried out at Tikur Anbessa Specialized Teaching Hospital (TASH) using cross sectional study design. A Simple random sampling method was used to select study participants. As a semi-structured questionnaire was used to collect data, mean, median and standard deviation were used to calculate direct cost indirect cost and companion side costs. Multiple linear regression analysis was employed to analyze the separate effects of the various predictor variables on cost of treatment.

Results: The average outpatient direct cost at Tikur Anbessa Specialized Teaching Hospital for breast cancer on chemo-therapy was 24953.45 ETB $(\$ 1188.26)$ SD $(=24874.77\{\$ 1184.51\})$. Direct medical cost comprised the largest part (mean=18753.41 ETB (893.02 USD) (SD=18860.95 ETB) \$898.14). Mean expenses for non-prescribed remedies was, 6200.00 birr $(\$ 295.24)$, takes the lion share of direct nonmedical cost followed by expense for transportation (mean=3568.31 ETB $\{\$ 169.92)$.

Conclusion: This study shows that the financial burden of breast cancer is substantial and overwhelming for both patients and their families. Outpatient treatment cost was found to be dependent on number of employed household members, number of facility visited. Longer duration of inpatient hospital stay and stages of breast cancer is associated with inpatient cost and indirect cost.
\end{abstract}

Keywords: Cost of Breast Cancer; Chemotherapy; Women; Ethiopia

Abbreviations: AAU: Addis Ababa University; ACIPH: Addis Continental Institute of Public Health; BC: Breast Cancer; FMOH: Federal Ministry of Health; GLOBOCAN: Global Burden of Cancer Study; IPD: In Patient Department; JHPIEGO: Johns Hopkins Program for International in Gynecology and Obstetrics; OPD: Out Patient Department; SPHMMC: St Paul's Hospital Millennium Medical College; TASH: Tikur Anbesa Specialized Hospital; US: United Stated of America

\section{Introduction}

Breast cancer is a malignant tumor that starts in the cells of the breast, it is found mostly in women [1]. Breast cancer is hormone related, and the factors that modify the risk of this cancer vary during premenopausal period. In both cases, there was convincing evidence that consuming alcoholic drinks increases the risk of this cancer and lactation protects against it. Abdominal fatness and adult weight gain are probably causes of this cancer and physical Activity probably protects against it [2]. A woman's life time risk is estimated as $9 \%$; for an individual woman, the risk of developing breast cancer is largely based on age, for instance, for ages 30 to 39 , the risk is $0.43 \%$, whereas for ages 60 to 69 , the risk is $3.65 \%$. In addition to age, the following are the possible risk factors for breast cancer are: fewer births, later age at first full-term pregnancy, not having breastfed, early age at menarche, irregular menses, late menopause, use of exogenous hormone (e.g. oral contraceptives, combined hormone therapy), obesity, physical inactivity, alcohol consumption, family history of breast cancer are some of the risk factors mentioned above [2-5].

Literatures on the costs and health effects of breast cancer control focuses mainly on developed countries and is difficult to generalize low-income countries, because of differences in context [6,7]. In the USA, for instance, BC drugs are the second biggest category of all pharmaceutical sales, this indicates that cost of breast cancer is high everywhere [8]. Financial costs incurred because of breast cancer and the effects of such costs on the family financial situation may constitute an important adverse consequence of this disease [9].

*Corresponding author: Gezahegn Mamo, Chief public health professional/ MPH In Health Economics, Principal Investigator, St. Paul's Hospital Millennium Medical College, Addis Ababa University, Ethiopia, Fax: +251112774787; E-mail: gezekiya@gmail.com

Received September 04, 2017; Accepted October 04, 2017; Published Octobe 12, 2017

Citation: Mamo G, Worku A, Lemma S, Demas T (2017) Cost of Illness of Breas Cancer Patients on Chemotherapy in Addis Ababa Public Hospitals, the Case of Tikur Anbessa Specialized Teaching Hospital-Cross-Sectional Types of Study. Health Econ Outcome Res Open Access 3: 142. doi: 10.4172/2471-268x.1000142

Copyright: ( 2017 Mamo G, et al. This is an open-access article distributed unde the terms of the Creative Commons Attribution License, which permits unrestricted use, distribution, and reproduction in any medium, provided the original author and source are credited. 
Citation: Mamo G, Worku A, Lemma S, Demas T (2017) Cost of Illness of Breast Cancer Patients on Chemotherapy in Addis Ababa Public Hospitals, the Case of Tikur Anbessa Specialized Teaching Hospital-Cross-Sectional Types of Study. Health Econ Outcome Res Open Access 3: 142. doi: 10.4172/2471-268X.1000142

Page 2 of 5

In recent years, female breast cancer cases are increasing in Ethiopia, for instance in the year 2012 total breast cancer cases were 12, 956 and $87 \%$ of them were below the age of 65 at the time of diagnosis and in 2015, the number of cases increased to 14,204 and similar proportion of them were below the age of $65 \mathrm{yr}$ [10].

One of the main reasons for delayed detection of breast cancer is the low level is breast self-examination among Ethiopian women [11]. There is also a huge financial strain on the patients and their care givers because the cost of treatment and follow-up [12]. This is severe in Ethiopia, since patients endure long appointment period for treatment from several weeks to months [13].

In Ethiopia, the burden of breast cancer is increasing from time to time. An estimated age-standardized incidence rate of 19.5 per 100, 000 and an estimated age-standardized death of 11.8 per 100, 000 females were reported [14].

According to GLOBOCAN report, in Ethiopia, estimated number of female breast cancer cases diagnosed were 12, 956 and estimated deaths with breast cancer were 7, 089 in 2012 [15]. According to the 5th National Health Account (NHA) of Ethiopia, the current out of pocket health care expenditure is $35.4 \%$ [16]. When out of pocket health care expenditure increases in a country, like Ethiopia, it imposes a household a financial catastrophe if there is no risk pooling mechanism [17].

The cost of treating breast cancer is increasing from time to time across the Globe. The economic burden of breast cancer is considerable in terms of both direct and indirect costs. The direct health care costs attributable to breast cancer vary greatly between countries, reflecting differences in total health care spending. Hospitalizations dominate the direct costs, but costs of pharmaceuticals are also high and increasing from time to time [18].

In the year 2010 , breast cancer costs $\$ 16.5$ billion in direct expenses in the US. In their lifetimes, each individual patient expected to spend between $\$ 20,000$ and $\$ 100,000$ for breast cancer treatment. In fact, as high as the number of direct costs is, indirect costs are even higher. The indirect costs include lost wages as a result of cancer treatment or cancer-related death [19].

Whereas in Vietnam, according to Hoang Lan et al. study, the estimated direct cost of breast cancer per patient was $\$ 975$. Stage at diagnosis was significantly associated with total treatment costs. Patients at later stages of breast cancer did not differ significantly in their total costs from those at earlier stages however, but their survival time was much shorter. The absence of health insurance was the main factor limiting service uptake [20].

\section{Methods}

\section{Study area and period}

A cross sectional study was conducted at Tikur Anbessa Specialized Hospital, Addis Ababa, Ethiopia. The study was approved by ethical review board of ACIPH and AAU. Tikur Anbessa Specialized Hospital (TASH) is one of the largest hospitals in Ethiopia which is found in Addis Ababa, the capital city of Ethiopia. The hospital comprises 200 doctors, 379 nurses and 115 other health professionals dedicated to provide health care service. The hospital opened in 1972G.C. and TASH is an 800 bed tertiary care teaching hospital of AAU. This hospital offers diagnosis and treatment for approximately 370,000 to 400, 000 patients per year (including breast cancer patients).
All women with breast cancer who are taking chemotherapy in outpatient and inpatient services in the selected public hospital (TASH) who were willing to give consent to participate in the study were eligible to be included.

The study period was from August-September 2016. The data was collected within this period. Semi-structured questionnaires were used to estimate cost of illness of breast cancer on patients and their family.

\section{Study design}

The study method was quantitative study using a hospital based cross-sectional design, and the cost of illness approach could be bottom up approach to estimate patient side costs of breast cancer who are taking chemotherapy.

\section{Statistical analysis}

The data entry was done using Epi Info version 7.1. Data cleanup was performed to check for accuracy, consistencies and values. Any error identified was corrected. The cleared data was exported to SPSS version 20 software for analysis. Data analysis was performed using frequency and percentage. A variety of descriptive statistics such as mean, standard deviation and median were calculated to describe some parts of the results.

Multiple linear regression analysis was employed to analyze the relationship between the cost (dependent variable) and potential predictor variables (independent variables). In the linear regression model, independent variables with a probability value of $\mathrm{P}$ statistics $<0.2$ on the simple linear regression model have been entered to multiple linear regression model (final model). Statistical significance was declared at $(\mathrm{P}<0.05)$.

\section{Results}

A total of 349 histologically confirmed and clinically staged breast cancer patients were selected from Oncology referral clinic (OPD) and Oncology ward, with the response rate of $91 \%$. For both departments specified sample size was provided ( $\mathrm{n}=262$ from Oncology OPD, and $\mathrm{n}=56$ from Oncology ward).

\section{Socio-demographic characteristics}

The mean age of the respondents was $43.2 \mathrm{yr}$. The youngest was 22 yrs old while the oldest respondent age was $75 \mathrm{yr}$ old. The total number of respondents in the age range of 22 yrs to 75 yrs were 317 (100\%). The majority of respondent, 387 (90.5\%) fell in to the age below 60 yrs (Table 1).

Data on the marital status reveals that more than half of the respondents, $173(54.4 \%)$ were currently married, In terms of educational status, most of the respondents, 171 (53.4\%) have a schooling of a high school or above. Majority of the respondents, 184 (58.0\%) indicated that they are orthodox Christians. The other variable which was considered in this section was occupational status of the respondents. The majority of the respondents, 103(32.5\%) were found to be civil servant followed by house wives $74(23.3 \%)$.

All the respondents, $317(100 \%)$ were able to report an estimate of the household monthly income. The majority of respondents, 202 (63.70\%) were earned a monthly income below 3500.00 ETB (166.7 USD). Monthly mean income was 5635.24 (3512.86) ETB \{mean: 268. USD: $S D=167.28$ USD $\}$ the median was 5000.00 ETB (23.81 USD) (Table 2) 
Citation: Mamo G, Worku A, Lemma S, Demas T (2017) Cost of Illness of Breast Cancer Patients on Chemotherapy in Addis Ababa Public Hospitals, the Case of Tikur Anbessa Specialized Teaching Hospital-Cross-Sectional Types of Study. Health Econ Outcome Res Open Access 3: 142. doi: 10.4172/2471-268X.1000142

Page 3 of 5

\begin{tabular}{|c|c|c|}
\hline Characteristics & Frequency & Percent \\
\hline \multicolumn{3}{|c|}{ 1. Age group } \\
\hline $20-29$ & 22 & 6.9 \\
\hline $30-39$ & 111 & 35 \\
\hline $40-49$ & 100 & 31.5 \\
\hline $50-59$ & 54 & 17 \\
\hline $60-69$ & 27 & 8.5 \\
\hline $70=79$ & 3 & 0.9 \\
\hline Total & 317 & 100 \\
\hline \multicolumn{3}{|c|}{ 2. Marital status } \\
\hline Single & 62 & 19.5 \\
\hline Married & 173 & 54.4 \\
\hline Widowed & 55 & 17.3 \\
\hline Separated & 21 & 6.6 \\
\hline Divorced & 7 & 2.2 \\
\hline \multicolumn{3}{|c|}{ 3. Occupation (n-317) } \\
\hline & 31 & 9.8 \\
\hline & 74 & 23.3 \\
\hline Farmer & 103 & 32.5 \\
\hline House wife & 16 & 5 \\
\hline NGO employed & 37 & 11.6 \\
\hline Merchant & 31 & 9.8 \\
\hline Student & 3 & 0.9 \\
\hline Daily labourer & 8 & 2.5 \\
\hline Unemployed & 1 & 0.3 \\
\hline Retired & 13 & 4.1 \\
\hline Disabled & 1 & 0.3 \\
\hline \multicolumn{3}{|c|}{ 4. Religion } \\
\hline Orthodox & 184 & 58.04 \\
\hline Protestant & 73 & 23.03 \\
\hline Muslim & 60 & 18.93 \\
\hline Catholic & 1 & 0.3 \\
\hline \multicolumn{3}{|c|}{ 5. Educational status } \\
\hline Illiterate & 58 & 18.3 \\
\hline Read and write & 50 & 17.77 \\
\hline Grade1-8 & 39 & 12.3 \\
\hline Grade9-12 & 77 & 24.29 \\
\hline College, University graduated & 93 & 29.34 \\
\hline College, University student & 1 & \\
\hline \multicolumn{3}{|c|}{ 6. Ethnicity } \\
\hline 1.Tigray & 50 & 17.77 \\
\hline 2.Amhara & 105 & 33.12 \\
\hline 3.Oromo & 107 & 33.75 \\
\hline 4.Gurage & 37 & 11.67 \\
\hline 5.Others & 19 & 5.99 \\
\hline \multicolumn{3}{|c|}{ 7. Family size } \\
\hline 01-Mar & 130 & 41 \\
\hline 04-Jun & 152 & 47.9 \\
\hline $.7-10$ & 35 & 11 \\
\hline Total & 317 & 100 \\
\hline
\end{tabular}

Table 1: Socio-demographic and socio-economic characteristics of study participants at TASH, 2016.

Out of 317 study participants, 304(95.90\%) of them have visited at least one of the providers at least once. More than half of the respondents were visited governmental health facility at least once before they came to TASH (Table 3). Outpatient cost out of Tikur Anbessa Specialized Teaching Hospital (TASH) Patient Side cost.

\section{Direct cost}

Out patients cost incurred out of TIKUR ANBESA Hospital; mean cost of consultation with physicians, investigations and treatments came to Ethiopian birr 81.55, 1810.84 and 999.07 respectively. From total direct cost components for investigations represents the largest share (62.63\%), followed by cost of drugs (34.55\%) (Table 4$)$.

\section{Companion side cost out of TASH}

Out of 317 respondents, $146(46.1 \%)$ of them who had visited health service providers had a family or friends who accompanied them. Thirty-nine (26.71\%) had lost their wages because they cared the study participants. Indirect cost was incurred by the Companions were 33,660 ETB (1602.86 USD) with the mean of 863.08 ETB (41.1 USD) and SD of 1107.44 ETB (52.74 USD).

\section{Outpatient cost at TASH}

Direct cost: The average outpatient direct cost at Tikur Anbessa Hospital for breast cancer treatment was 24953.45 ETB (1188.26 USD) $\{\mathrm{SD}=24874.77 \mathrm{ETB}$ (1184.21 USD) $\}$. Direct medical costs comprised the largest part, 18753.41 ETB (893.02 USD) (SD=18860.95 ETB) 898.14 USD\}. Mean expenses for non-prescribed remedies was, 6200.00 birr (295.24 USD), takes the lion share of direct nonmedical cost followed by expense for transportation (mean=3568.31 ETB) (169.92 USD).

Indirect cost: Total forgone earning born by the study participants because of hospital stay was $1,118,264.46$ birr (mean=3527.65 and $\mathrm{SD}=6278.38$ ) due to 5,288 working day lost (mean=16.7 and median 15$)$.

Companion side cost: The mean direct cost of companion was 3038.50 ETB (144.69 USD) and the mean indirect cost was 1188.85 ETB (56.61 USD) (Table 5).

\section{Discussion}

The mean age of the respondents was 43.2. Majority of them are house wives. That means, they are unemployed, are dependent on their spouses or their families. Vast majority of them are diagnosed at advanced stages (III-IV), this can be the cause for high cost of treatment.

\begin{tabular}{|c|c|c|c|c|c|}
\hline $\begin{array}{c}\text { Number of } \\
\text { HH member } \\
\text { employed }\end{array}$ & Frequency & $\begin{array}{c}\text { Valid } \\
\text { percent }\end{array}$ & $\begin{array}{c}\text { HH income in } \\
\text { ETB }\end{array}$ & Frequency & $\begin{array}{c}\text { Valid } \\
\text { percent }\end{array}$ \\
\hline 1 & 69 & 22.2 & $500.00-1500.00$ & 70 & 22.1 \\
\hline 2 & 142 & 45.7 & $1501.00-2500.00$ & 75 & 23.7 \\
\hline 3 & 55 & 17.7 & $2501.00-3500.00$ & 57 & 18 \\
\hline 4 & 34 & 10.9 & $3501.00-4500.00$ & 58 & 18.3 \\
\hline 5 & 9 & 2.9 & $4501.00-5500.00$ & 27 & 8.5 \\
\hline 6 & 1 & 0.3 & $5501.00-6500$ & 10 & 3.2 \\
\hline 7 & 1 & 0.3 & Above 6500.00 & 20 & 6.3 \\
\hline Total & 311 & & & & \\
\hline
\end{tabular}

Table 2: Shows no. of household member of study participants who are employed and their income category.

\begin{tabular}{|c|c|c|}
\hline Service providers & Frequency & Valid percent \\
\hline Government health facility & 186 & 61.2 \\
\hline NGO health facility & 104 & 34.2 \\
\hline Private health facility & 11 & 3.6 \\
\hline Traditional healers & 3 & 1.0 \\
\hline Total & 304 & 100.0 \\
\hline
\end{tabular}

Table 3: Percent distribution of service provider visited by the respondents at TASH. 
Citation: Mamo G, Worku A, Lemma S, Demas T (2017) Cost of Illness of Breast Cancer Patients on Chemotherapy in Addis Ababa Public Hospitals, the Case of Tikur Anbessa Specialized Teaching Hospital-Cross-Sectional Types of Study. Health Econ Outcome Res Open Access 3: 142. doi: 10.4172/2471-268X.1000142

Page 4 of 5

\begin{tabular}{|c|c|c|c|}
\hline $\begin{array}{c}\text { Direct outpatient cost(in ETB) out of TIKUR ANBESA } \\
\text { Hospital (in ETB and in US dollars) }\end{array}$ & Mean & Median & SD (standard deviation) \\
\hline \multicolumn{4}{|c|}{ Direct medical cost } \\
\hline Consultation fee (card fee) $(n=298)$ & 81.55 (3.88USD) & 20.00 (0.95USD) & 107.63 (5.13USD) \\
\hline Investigation fee $(n=300)$ & 1810.84 (86.23USD) & 1320.00 (62.86USD) & 2050.15 (97.63USD) \\
\hline Cost of medication $(n=299$ & 999.07 (47.57USD) & 350.00 (16.67USD) & 1773.21(84.44USD) \\
\hline \multicolumn{4}{|c|}{ Direct-non-medical cost } \\
\hline Transportation fee+ other cost & 498.38 (23.73USD) & 80 (3.81USD) & 1523.91 (72.57USD) \\
\hline Direct medical cost at TASH & 18753.41ETB (893.02USD) & 13330.00ETB (634.76USD) & 18860.95ETB (898.14USD) \\
\hline Direct non-medical cost at TASH & 6200.00 (295.24USD) & 2600.00 (123.81USD) & $7724.20(367.82)$ \\
\hline Transportation fee $(n=307)$ & 3568.31 (169.92USD ) & 700.00 (33.33USD) & 6799.02 (323.77USD) \\
\hline
\end{tabular}

Table 4: Patient side direct outpatient costs of breast cancer patients on chemotherapy out of and At TASH In ETB and US dollar ( for $2015 / 16$ was 1 USD=21.00ETB).

\begin{tabular}{|c|c|c|}
\hline $\begin{array}{c}\text { Direct cost } \\
\text { Transportation fee+cost for other } \\
\text { expenses(n=194) }\end{array}$ & Mean & Median \\
\cline { 2 - 4 } & $3038.50(144.69$ SSD) & 1200.00 (57.14USD) \\
\hline Indirect cost amount of wage lost $(\mathbf{n}=\mathbf{7 9})$ & $1188.85(56.61 \mathrm{USD})$ & 750.00 (35.71USD) \\
\hline
\end{tabular}

Table 5: Companion side direct and indirect cost of breast cancer at TIKUR ANBESA, Addis Ababa, Ethiopia, 2016.

To know which clinical and socio-demographic factors affect the patient side costs, a multiple linear regression model was fitted cost data for both outpatient and inpatient cost. The socio-demographic (age category), family size), economic (household income) and clinical (current stages of breast cancer) variables were taken into consideration.

The multiple linear regression models include six independent variables. All of them are significantly associated with patient's side costs of breast cancer $((\mathrm{P}<0.05)$ : Age group, number of family member who are employed, current stage, Income category, number of health facility visited and duration of stay at hospital.

The six variables together give an adjusted $\mathrm{R} 2$ value of $42 \%$ \{ $(6$, 39.18), $\mathrm{P}=0.000\}$. This indicates that the variability in the cost was $42 \%$ explained by the predictor variables in the model.

According to the model, Age category, number of family member employed, current stage of breast cancer and amount of monthly income, number of health facility visited and duration of stay at hospital were associated with the higher patient side cost.

Variation was seen among the study participants regarding the time interval from onset of the disease symptom up to the diagnosis at Tikur Anbessa Hospital, from one month up to 50 months. These figures indicate that, there was a delayed in treatment seeking. This could be because of: lack of transportation, lack of health seeking behavior or lack of money to treat. Accuracy of diagnosis due to lack of access to diagnostic materials, the quality and referral linkage is also considered [21]. There has been no previous study in cost of breast cancer study in Ethiopia as well as in sub Saharan Africa.

The average outpatient cost per patient for breast cancer was 24953.45 ETB (1188.26 USD) \{SD=24874.77 ETB (1184.51 USD)\}.

This finding is slightly higher as compared to the study in Vietnan, 975 USD (22), As compared to the study done in Canada, 1002 USD [23]. and also higher than study done in Karachi (Pakistan), 1093.13 USD [24], but lower as compared to the study done in Germany[25]. These differences may be due to different study design or due to difference in study period.

\section{Conclusion}

This study was planned to answer the two main research questions: How much financial burden do have on breast cancer patients, and their families, care-givers and on the society at large? The second question was: what are the predictors (variables) that explain the variation of patient side cost in different group? Despite its limitation, this cost of illness study is the ground breaker for estimating the direct and indirect costs associated with the breast cancer illness in Ethiopia.

This study indicates that the financial burden of breast cancer is substantial and can be overwhelming. There is a desperate need for the treatment support programs either by government or by NGOs to support patients and their families.

\section{Strengths and limitations}

\section{Strengths:}

- This cost of illness study estimates cost from societal perspective, which may enable us to include more cost components.

- The study used approach that did not require normative assumptions.

\section{Limitations:}

- This cost of illness study is limited to patient side cost and their care givers (companion cost).

- Productivity lost (indirect cost) was calculated estimated on subjective scale.

- The data on expenditure and household income could be biased.

\section{Ethics Approval and Consent to Participate}

Ethical clearance was obtained from Institutional Research Board of Addis continental institute of public health, the purpose and method of the study was explained to the Tikur Anbessa specialized Hospital (TASH) and Addis Ababa University (AAU) Institutional Research Board and obtained permission. Further, informed consent was obtained from each study participants before data collection. Confidentiality and privacy of participants was ensured at all levels throughout the study by keeping data anonyms and keeping the data and records in a safe place.

Moreover, a confirmation of the consent by the client was obtained by signing a consent form. In all cases, the study proceeded after obtaining an informed consent from the respondents. The data 
Citation: Mamo G, Worku A, Lemma S, Demas T (2017) Cost of Illness of Breast Cancer Patients on Chemotherapy in Addis Ababa Public Hospitals, the Case of Tikur Anbessa Specialized Teaching Hospital-Cross-Sectional Types of Study. Health Econ Outcome Res Open Access 3: 142. doi: 10.4172/2471-268X.1000142

collectors were assured the participant that, there was nothing that harms them and compensates their safety by participating in the study before the interview. Participation was on voluntary bases and participants were free to withdraw at any time during the interview process.

To secure confidentiality all data collected from patients and investigator collected the filled out data was stayed with the investigator secured place.

\section{Availability of Data and Materials}

The datasets used to analyze this research will be available from the corresponding author (GM) on reasonable request and the questionnaire is attached as Additional file 1.

\section{Authors' Contributions}

GM has taken the lead role in writing the proposal, submission and follow up for ethical review, data collection, data entry, writing the preliminary results and final manuscript. AW performed statistical analysis, reviewing and editing the final draft of the manuscript. S L participated in designing the study, reviewing and editing the final draft of the manuscript. T D participated in designing the study and reviewing the final draft of the manuscript. All authors read and approved the final manuscript.

\section{Acknowledgements}

As a corresponding author, I would like to first say a very big thank you to ACIPH for giving me this chance to be a part of 2016 batch. The Authors gratefully acknowledge the funding source: JHPIEGO, SPHMMC and FMOH. All SPHMMC supervision staffs, data collectors this accomplishment would not have been possible without you, thank you all.

\section{References}

1. Colditz GA, Bohlke K, Berkey CS (2014) Breast cancer risk accumulation starts early - Prevention must also. Breast Cancer Res Treat 145: 567-579.

2. Gray JM, Rasanayagam S, Engel C, Rizzo J (2017) State of the evidence 2017: An update on the connection between breast cancer and the environment. Environ Health 2: 16

3. Howell A, Anderson AS, Clarke RB, Duffy SW, Evans DG, et al. (2014) Risk determination and prevention of breast cancer. Breast Cancer Res 16: 446.

4. Gandhi S, Verma S (2011) Early Breast Cancer in the Older Woman. The Oncologist 16: 479-485.
5. Zelle SG, Nyarko KM, Bosu WK, Aikins M, Niëns LM, et al. (2012) Costs, effects and cost-effectiveness of breast cancer control in Ghana: Breast cancer control Ghana. Trop Med Int Health 17: 1031-1043.

6. Kim YA, Oh IH, Yoon SJ, Kim HJ, Seo HY, et al. (2015) The economic burden of breast cancer in Korea from 2007-2010. Cancer Res Treat off $\mathrm{J}$ Korean Cancer Assoc 47: 583-590

7. Carles M, Vilaprinyo E, Cots F, Gregori A, Pla R, Román R, et al. (2011) Costeffectiveness of early detection of breast cancer in Catalonia (Spain). Bmc Cancer 11: 1.

8. Lauzier S, Levesque P, Mondor M, Drolet M, Coyle D, et al. (2013) Out-ofpocket costs in the year after early breast cancer among canadian women and spouses. JNCI J Natl Cancer Inst 105: 280-292.

9. GLOBOCAN (2012) Cancer Incidence, Mortality and Prevalence Worldwide.

10. Birhane N, Mamo A, Girma E, Asfaw S (2015) Predictors of breast selfexamination among female teachers in Ethiopia using health belief model. Arch Public Health 73: 1.

11. Paying for Your Care After a Breast Cancer Diagnosis.

12. Abate SM, Yilma Z, Assefa M, Tigeneh W (2016) Trends of breast cancer in Ethiopia. Int J Cancer Res Mol Mech 2: 1.

13. Kantelhardt EJ, Zerche $P$, Mathewos A, Trocchi P, Addissie A, et al. (2014) Breast cancer survival in Ethiopia: a cohort study of 1,070 women. Int J Cancer 135: 702-709.

14. http://globocan.iarc.fr/old/pie_pop.asp?selection=61231\&title=Ethiopia\&sex $=2$ \&type $=0$ \& window $=1$ \&join $=1$ \& submit $=\% \mathrm{C} 2 \% \mathrm{~A} 0$ Execute $\% \mathrm{C} 2 \% \mathrm{~A} 0$

15. http://www.indexmundi.com/facts/ethiopia/indicator/SH.XPD.OOPC.TO.ZS

16. Beogo I, Huang N, Gagnon MP, Amendah DD (2016) Out-of-pocket expenditure and its determinants in the context of private healthcare sector expansion in sub-Saharan Africa urban cities: Evidence from household survey in Ouagadougou, Burkina Faso. BMC Res Notes 9: 3.

17. Cost of illness for breast cancer patients \& global burden.

18. Breast Cancer by the Numbers: Facts and Statistics. Healthline.

19. Hoang Lan N, Laohasiriwong W, Stewart JF, Tung ND, Coyte PC (2013) Cos of treatment for breast cancer in central Vietnam. Glob Health Action 2013: 6

20. Zaidi AA, Ansari TZ, Khan A (2012) The financial burden of cancer: Estimates from patients undergoing cancer care in a tertiary care hospital. Int $J$ Equity Health 11: 1.

21. Gruber EV, Stock S, Stollenwerk B (2012) Breast Cancer Attributable Costs in Germany: A Top-Down Approach Based on Sickness Funds Data. de Boer A (ed.) PLoS ONE 7: e51312. 